\title{
The role of DNMT1/hsa-miR-124-3p/BCAT1 pathway in regulating growth and invasion of esophageal squamous cell carcinoma
}

Bo Zeng ${ }^{1 \dagger}$, Xin Zhang ${ }^{1 \dagger}$, Jingling Zhao ${ }^{2 \dagger}$, Zhewei $\mathrm{Wei}^{3}$, Haoshuai Zhu' ${ }^{1}$, Minyi Fu ${ }^{4}$, Dawei Zou', Yanfen Feng ${ }^{5,6,7^{*}}$, Honghe Luo ${ }^{1,7^{*}}$ and Yiyan Lei ${ }^{1,7^{*}}$

\begin{abstract}
Background: Esophageal squamous cell carcinoma (ESCC) is the major subtype of esophageal cancer with high aggressiveness and poor prognosis. There is an urgent need for understanding the molecular mechanism underlying the development and progression of ESCC.

Methods: ESCC tissues and corresponding non-neoplastic tissues were collected. The expression and function of miR-124-3p and BCAT1 in two cell lines KYSE-150 and Eca109 were determined.

Results: We show downregulation of miR-124-3p expression in ESCC tissues, which is highly correlated with proliferation and migration of ESCC cell lines KYSE-150 and Eca109. miR-124-3p show high correlation with TNM stage and differentiation grade. Furthermore, miR-124-3p directly targets mRNA 3'UTR region of BCAT1, which results in upregulation of BCAT1 expression as observed in ESCC tissues and cell lines. Also, our data indicates that BCAT1 high expression is strongly linked to the disease-free survival, tumor size, pathologic stage, $T$ classification and differentiation grade. On the other hand, we clarified the upstream mechanism regulating miR-124-3p expression in ESCC, which involves in the hypermethylation-silencing regulation mediated by DNA methyltransferase 1(DNMT1), which is of high expression in ESCC tissues and cell lines in the present study. In addition, DNMT1 knockdown or inhibition of DNMT1 function contributes to downregulation of miR-124-3p and BCAT1 expression.
\end{abstract}

Conclusions: Our study thus clarifies a new mechanism that DNMT1/miR-124/BCAT1 axis regulates the development and progression of ESCC.

Keywords: Esophageal squamous cell carcinoma, Hsa-miR-124-3p, Branched chain amino acid transaminase 1, DNA methyltransferase 1

\section{Background}

Esophageal cancer is one of the most common cancers with high aggressiveness and poor prognosis [1]. Esophageal squamous cell carcinoma (ESCC) is the major subtype of esophageal cancer and is highly prevalent in China [2]. Despite substantial improvements in clinical

\footnotetext{
* Correspondence: fengyf@sysucc.org.cn; Luohhzm@163.com; leiyiyan@mail.sysu.edu.cn; yiyanldoc@163.com

${ }^{\dagger}$ Bo Zeng, Xin Zhang and Jingling Zhao contributed equally to this work. ${ }^{5}$ State Key Laboratory of Oncology in South China, Collaborative Innovation Center for Cancer Medicine, Sun Yat-sen University Cancer Center, Guangzhou, China

${ }^{1}$ Department of Thoracic Surgery, the First Affiliated Hospital, Sun Yat-sen University, Guangzhou, China

Full list of author information is available at the end of the article
}

diagnosis and therapeutics over the past two decades, the 5-year survival rate in patients with ESCC is less than $25 \%$ [3]. There is an urgent need for understanding the molecular mechanism underlying the development and progression of ESCC.

In recent years, cancers have been widely regarded to be associated with epigenetic modifications that is defined as a stable change in gene expression without modifications in DNA sequence [4-6]. DNA methylation is one of the best known epigenetic mechanisms in cancer epigenetics. DNA methylation involves in the addition of a methyl $(\mathrm{CH} 3)$ group to DNA with DNA methyltransferases (DNMTs), thereby often modifying gene function through regulation of gene expression [7].

(c) The Author(s). 2019 Open Access This article is distributed under the terms of the Creative Commons Attribution 4.0 International License (http://creativecommons.org/licenses/by/4.0/), which permits unrestricted use, distribution, and reproduction in any medium, provided you give appropriate credit to the original author(s) and the source, provide a link to the Creative Commons license, and indicate if changes were made. The Creative Commons Public Domain Dedication waiver (http://creativecommons.org/publicdomain/zero/1.0/) applies to the data made available in this article, unless otherwise stated. 
DNA hypermethylation in the promotor region of tumor suppressor genes has been widely shown in various cancers $[8,9]$. Similarly, a recent study on ESCC also showed aberrant DNA methylation in the different genes including HOXB2, NEFL, SLC15A3, OBSL1 and miR124 [10]. However, it is lack of evidence that these genes are essentially associated with ESCC progression. Among of these genes, miR-124 caught our attention in view of the finding that large number of microRNAs(MiRNAs) have been shown important roles in the development of different cancers [11]. In the previous studies, miR-124 has been shown to be associated with several cancers including ESCC [10, 12]. For instance, miR-124 might have effects on decreasing risks of ESCC in subgroups of Chinese elderly persons [13].

A microRNA is a small non-coding RNA molecule, which functions in the post-transcriptional regulation of gene expression by partially complementing with the 3 'untranslated regions (3'UTR) of specific mRNAs [14]. According to the prediction of bioinformatics software of Miranda, we showed that 5'-UTR regions of hsamiR-124-3p, a mature sequence of human miR-124 precursor, could bind to 3'-UTR region of branched chain amino acid transaminase 1(BCAT1) gene, the enzyme that catalyzes branched-chain alpha-keto acids to branched-chain L-amino acids essential for cell growth $[15,16]$. BCAT1 overexpression has been shown to be associated with several cancers including glioblastoma [17], nasopharyngeal carcinoma [18], ovarian cancer [19] and hepatocellular carcinoma [20].

These findings prompted us to investigate the role of DNMT/miR-124/BCAT1 axis in regulating development and progression of ESCC. With the study of loss-offunction and gain-of-function in DNMT/miR-124/ BCAT1, we showed that downregulation of hsa-miR124-3p in ESCC tissues and cells contributed to the upregulation of BCAT1 expression, which enhanced the proliferation and invasion of ESCC. Furthermore, the data demonstrated that hsa-miR-124-3p downregulation was associated with hypermethylation in its promotor region, which resulted from increased expression of DNMT1. Our study thus clarifies a new mechanism that DNMT1/miR-124/BCAT1 axis regulates the development and progression of ESCC. These findings suggest that inhibitors against the activity of DNMT1 and/or BCAT1 might be a novel strategy to inhibit development and progression of ESCC.

\section{Methods}

\section{Patients and tissue samples}

The primary ESCC tissues and adjacent normal tissues were collected from patients who underwent surgery the First Affiliated Hospital, Sun Yat-sen University. All patients have not received any therapy before surgery. The specimens were collected immediately after removing the resected esophagus, and stored at $-80^{\circ} \mathrm{C}$. The study was obtained the informed consent from all the participating patients and the approval from the Ethics Committee of the First Affiliated Hospital, Sun Yat-sen University.

\section{Cell culture, cell transfection and drug treatment}

Human normal esophageal cell line HEEC (Het-1A, ATCC $^{\ominus}$ CRL-2692 $2^{\text {mo }}$ ) was obtained from the America Type Culture Collection in May 2017, and two human esophageal carcinoma cell lines, KYSE-150 (TCHu236) and Eca-109 (TCHu69), were obtained from Shanghai Institute of Biological Sciences, Chinese Academy of Sciences in May 2017. These cell lines have been authenticated by short-tandem repeat analyses. They are free of mycoplasma contamination.

The cells were maintained in RPMI-1640 medium (Invitrogen, Carlsbad, CA, USA) supplemented with 10\% FBS (Gibco, Grand Island, NY, USA) and 1\% PenicillinStreptomycin (10,000 U/mL) (Invitrogen). For cell transfection, siRNAs including DNMT1 siRNA, BCAT1 siRNA, scrambled siRNA (NC siRNA), miR-124-3p mimics and its negative control (NC mimics) were supplied by Ribobio Company (Guangzhou, China) and pcDNA-BCAT1(OE-BCAT1) or pcDNA-negative (OE$\mathrm{NC})$ were constructed using pcDNA3.1(+) vector. KYSE-150 and Eca-109 cells grown in 6-well cell plates $\left(1 \times 10^{6}\right)$ were transfected with siRNA or pcDNA3.1vector using Lipofectamine 2000 (Invitrogen) according to the manufacturer's instruction. After $6 \mathrm{~h}$, the transfection solution was replaced by complete medium.

For drug treatment, KYSE-150 or Eca109 cells were treated with $5 \mu \mathrm{M}$ 5-Azacitidine (5-Aza, Sigma-Aldrich, Saint Louis, MO, USA), which is the inhibitor of DNMT1.

\section{Real-time PCR}

Total RNA from tissue samples and cells were extracted with RNAprep pure tissue kit (Tiangen Biotech Co., LTD., Beijing, China) and Rneasy Mini Kit (Qiagen, Germantown, MD, USA) respectively. The mRNA of DNMT1, miR-124-3p and BCAT1 were amplified by quantitative real-time RT-PCR. It was carried out using SuperScriptIII Platinum SYBR Green One-Step qRTPCR kit (Invitrogen) by an ABI 7500 Fast real-time PCR instrument (Applied Biosystems, Foster City, CA, USA). It was carried out with the following procedures: $50^{\circ} \mathrm{C}$ for $3 \mathrm{~min}, 95^{\circ} \mathrm{C}$ for $5 \mathrm{~min}$, followed by 35 cycles of $95^{\circ} \mathrm{C}$ for $15 \mathrm{~s}, 60^{\circ} \mathrm{C}$ for $30 \mathrm{~s}$. The specific primers used in quantitative real-time RT-PCR were displayed as follows: DNMT1: forward, 5'-CCTAGCCCCAGGATTACAAG G-3'; reverse, 5' -ACTCATCCGATTTGGCTCTTTC-3'; BCAT1: forward: 5' - GAGCCTGGAAAGGTGGAACT 
G-3'; reverse, 5' - GCTGACACCCATTATCTACTGCT3'; GAPDH: forward, 5'-TGTTCGTCATGGGTGTGA AC-3'; reverse, 5'-ATGGCATGGACTGTGGTCAT-3'; hsa-miR-124-3p: forward, 5'-ACACTC CAGCTGGGT AAGGCACGCGGTGAA-3'; reverse, 5' - CTCAACTGG TGTCGTGGAGTCGGCAATTCAGTTGAGGGCATTC AC-3; U6: forward, 5'-CTCGCTTCGGCAGCACA-3'; reverse, 5'-AACGCTTCACGAATTTGCGT-3'. The data were analyzed according to the comparative $\mathrm{Ct}$ method.

\section{Bisulfite sanger sequencing}

Genomic DNA from ESCC tissues or adjacent normal tissues was extracted using QIAamp DNA Mini Kit (Qiagen) and bisulfite converted using an EpiTect Bisulfite Kit (QIAGEN). The hsa-miR-124-3p was enriched by PCR with Taq DNA Polymerase (Invitrogen) and primer designed using Pyrosequencing Assay Design Software (Qiagen). The PCR products were cloned into pGEMT vector, then subjected to Sanger sequencing. Five single molecules were sequenced for each sample.

\section{Methylation specific PCR (MSP)}

The bisulfite converted DNAs were used as the templates for the MSP assay, with miR-124-3p primers that distinguish the methylated (M) from unmethylated (U) DNA: $M$ forward: 5'-GTATTTGGGGGTTTATTTTT TGTC-3'; M reverse: 5' - GAAACCGACTCGAACTTA CGTA-3'; U forward: 5'-GTATTTGGGGGTTTATTT TTTGTT-3'; U reverse: 5'-ATCAAAACCAACTCAA ACTTACATA-3'. PCR amplification was conducted at $95^{\circ} \mathrm{C}$ for $3 \mathrm{~min}$, followed by 30 cycles of $94^{\circ} \mathrm{C}$ for $1 \mathrm{~min}$, $56^{\circ} \mathrm{C}$ for $1 \mathrm{~min}, 72^{\circ} \mathrm{C}$ for $30 \mathrm{~s}$, and the elongation at $72{ }^{\circ} \mathrm{C}$ for $5 \mathrm{~min}$. A plasmid containing methylated miR124-3p sequence and water without DNA template were used as positive control and negative control, respectively. Finally, MSP products were analyzed using agarose gel electrophoresis.

\section{Prediction of hsa-miR-124-3p targets}

The target of hsa-miR-124-3p was predicted with the online software Miranda, which is an algorithm for determining potential target sites of microRNA in genomic sequences. Briefly, hsa-miR-124-3p sequences were first scanned in all genomic DNA/RNA sequences. Then, the potential target sites were identified with a dynamic programming local alignment and the thermodynamic stability estimation of RNA duplexes. The detected target with energies less than an energy threshold was identified as potential target sites.

\section{Luciferase assay}

The human BCAT1 3'-UTR DNA sequence that was predicted to interact with miR-124-3p and the mutant BCAT1 3'-UTR DNA sequence were amplified and inserted into psi-CHECK2 renilla/firefly dual-luciferase expression vector (Promega, Mullion, WI, USA), with the following primers: BCAT1-WT-1: 5'-CCGCTCGAG TTTGAAGGTCCTCCAAGTCCGTGT-3' (forward) and 5' -ATTTGCGGCCGCCTAATGCTGCCACTGAGCTGA CAAG-3' (reverse). BCAT1-MUT-1: 5'-AAGACTGAGG GTCTTCGCATACATAGATCTTTGTATC-3' (forward) and 5'-GATACAAAGATCTATGTATGCGAAGACCCTC AGTCTT-3' (reverse). BCAT1-WT-2: 5'-CCGCTCGAGGAGGGTGATGACATACATTTACTGG-3' (forward) and $5^{\prime}$-ATTTGCGGCCGCAACTTTTCAGAATCCCTA GTGGC-3' (reverse). BCAT1-MUT-2: 5' -ATTCCATATACATATCGCATACATATTGTGATAATTT-3' (forward) and 5'-AAATTATCACAATATGTATGCGATATGTATA TGGAAT-3' (reverse). KYSE-150 or Eca-109 cells were co-transfected with the BCAT1-WT/BCAT1-MUT reporter constructs, and miR-124-3p mimics/NC mimics with Lipofectamine 2000 (Invitrogen). Luciferase activities were determined after $48 \mathrm{~h}$ using the Dual-Luciferase reporter assay system (Promega) on Enspire. Data are presented as the ratio of renilla luciferase activity to firefly luciferase.

\section{Immunohistochemistry staining}

ESCC tissue or adjacent normal tissue samples were fixed in $10 \%$ neutral buffered formalin (NBF). Thereafter, the tissues were paraffin-processed and embedded. The deparaffinized tissue sections $(4 \mathrm{~mm}$ thick) were stained with antibody against BCAT1 (Santa Cruz, Dallas, Texas, USA) for immunohistochemical analysis. Images of immunohistochemistry staining were photographed under a light microscope (Leica, Wetzlar, Germany).

\section{Western blot analysis}

Total cell proteins were extracted using the mammalian protein extraction reagent including halt protease inhibitor cocktail (Thermo Fisher Scientific, Waltham, MA, USA). The protein concentrations were measured by BCA protein assay kit (Thermo Fisher Scientific) and equal amount of proteins were subjected to SDS-PAGE, then transferred to polyvinylidene difluoride membranes (Millipore, Billerica, MA, USA). After blocked with 5\% nonfat milk, the membranes were incubated with primary antibodies against DNMT1, BCAT1, and GAPDH (Santa Cruz), respectively, and followed by incubation with the HRP-conjugated secondary antibodies. The signals were detected using an enhanced chemiluminescence kit (GE Healthcare Life Sciences, Pittsburgh, PA, USA).

\section{Immunofluorescence staining}

KYSE-150 or Eca-109 cells grown on coverslips were treated with miR-124-3p mimics/NC mimics or BCAT1 siRNA/NC siRNA for $48 \mathrm{~h}$. Then the cells were fixed 
with $4 \%$ paraformaldehyde and permeabilized with $0.5 \%$ Triton X-100 in PBS. After blocked with 3\% bovine serum albumin, cells were incubated with primary antibodies against DNMT1, BCAT1 and DAPI. Subsequently, cells were stained with the Alexa Fluor 488conjugated and FITC-conjugated secondary antibodies (BD Biosciences, San Diego, CA, USA). Finally, immunofluorescence images were visualized under LSM 510 Meta confocal microscope (Carl Zeiss $\mathrm{GmbH}$, Oberkochen, Germany).

\section{CCK-8 assay}

Cell viability was measured using Cell Counting Kit-8 (CCK-8) (Dojindo, Kumamoto, Japan). KYSE-150 or Eca-109 cells grown in 96-well plates were treated with miR-124-3p mimics/NC mimics or BCAT1 siRNA/NC siRNA for $24 \mathrm{~h}, 48 \mathrm{~h}$ or $72 \mathrm{~h}$. After washing with PBS for three times. A 1:10 diluted CCK-8 solution was added and incubated at $37^{\circ} \mathrm{C}$ for $2 \mathrm{~h}$. The absorbance was determined at $450 \mathrm{~nm}$ on Enspire (PerkinElmer, Waltham, MA, USA).
A

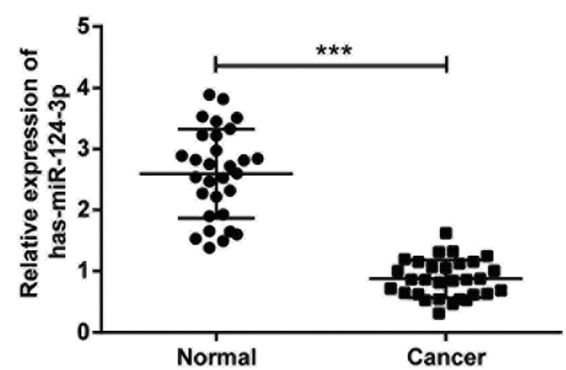

C

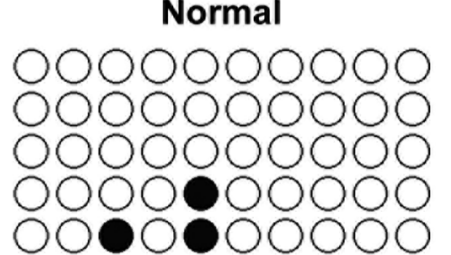

B

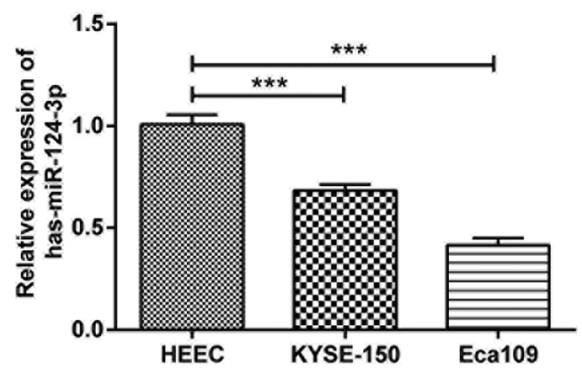

cancer

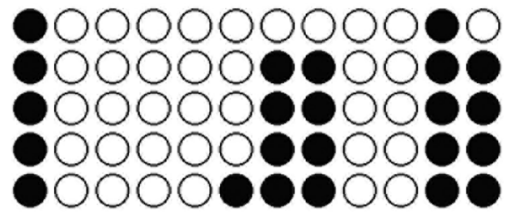

D
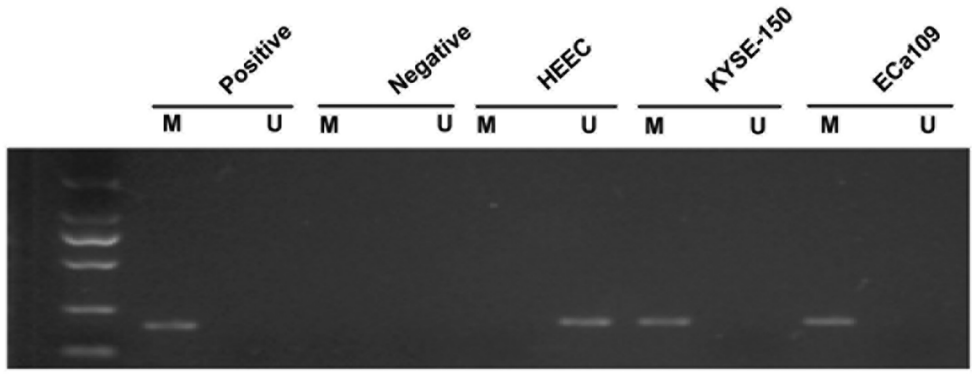

E

$\mathbf{F}$
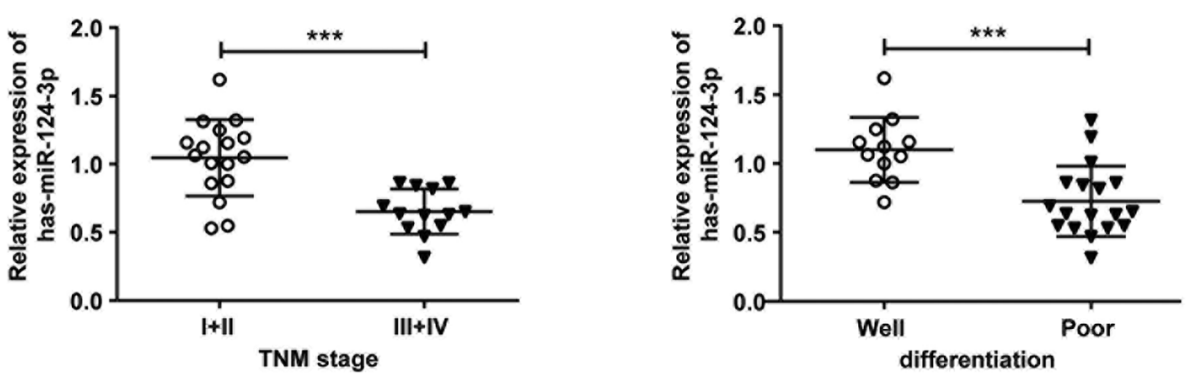

Fig. 1 The expression and hypermethylation of hsa-miR-124-3p in ESCC tissues and cells. The mRNA expression of hsa-miR-124-3p in normal tissues and ESCC tissues (a) and its expression in HEEC, KYSE-150 and Eca109 cells (b) were determined by qRT-PCR analysis. The methylation status of hsa-miR-124-3p in normal tissues and ESCC tissues (c) and its status in HEEC, KYSE-150 and Eca109 cells (d) were determined by bisulfite Sanger sequencing and methylation specific PCR respectively. hsa-miR-124-3p expression in tumor tissues was shown in the patents with different TNM stages $(\mathbf{e})$ and different differentiation $(\mathbf{f})$. Experiments were performed in triplicate and each value represents $m e a n \pm S D$. ${ }^{* * *} P<0.001$ 


\section{Colony formation assay}

For colony formation assay, KYSE-150 or Eca-109 cells treated with miR-124-3p mimics/NC mimics or BCAT1 siRNA/NC siRNA were seeded in a $3 \mathrm{~mm}^{2}$ plate. After 2 weeks of incubation, plates were washed with PBS gently and stained with $0.5 \%$ crystal violet in $20 \%$ ethanol for $15 \mathrm{~min}$ at room temperature. Lastly, the cells were imaged after rinsed with PBS.

\section{Transwell assay}

The invasion capability of cells was determined by the transwell assay. After transfection for $48 \mathrm{~h}$, KYSE-150 or Eca-109 cells in serum-free media were transferred into the upper chamber of Transwell assay inserts (Millipore) and media supplemented 10\% FBS was added to the bottom chamber. After incubation at $37^{\circ} \mathrm{C}$ for $24 \mathrm{~h}$, the invading cells through the membrane were stained with $0.5 \%$ crystal violet in $20 \%$ ethanol and photographed under the light microscope.

\section{Results}

Expression of hsa-miR-124-3p is down-regulated and its gene shows hypermethylation in ESCC tissues and cells Considering that MIR124-2 gene has been reported to be of high methylation in ESCC, we supposed that the mRNA expression of hsa-miR-124-3p, as a mature sequence, was influenced in ESCC tissues and cells. As indicated in Fig. 1a, hsa-miR-124-3p mRNA expression was significantly decreased in ESCC tissues compared with adjacent normal tissues. Meanwhile, its expression was also attenuated in ESCC cell line KYSE-150 and Eca109 cells compared with noncancerous HEEC cells

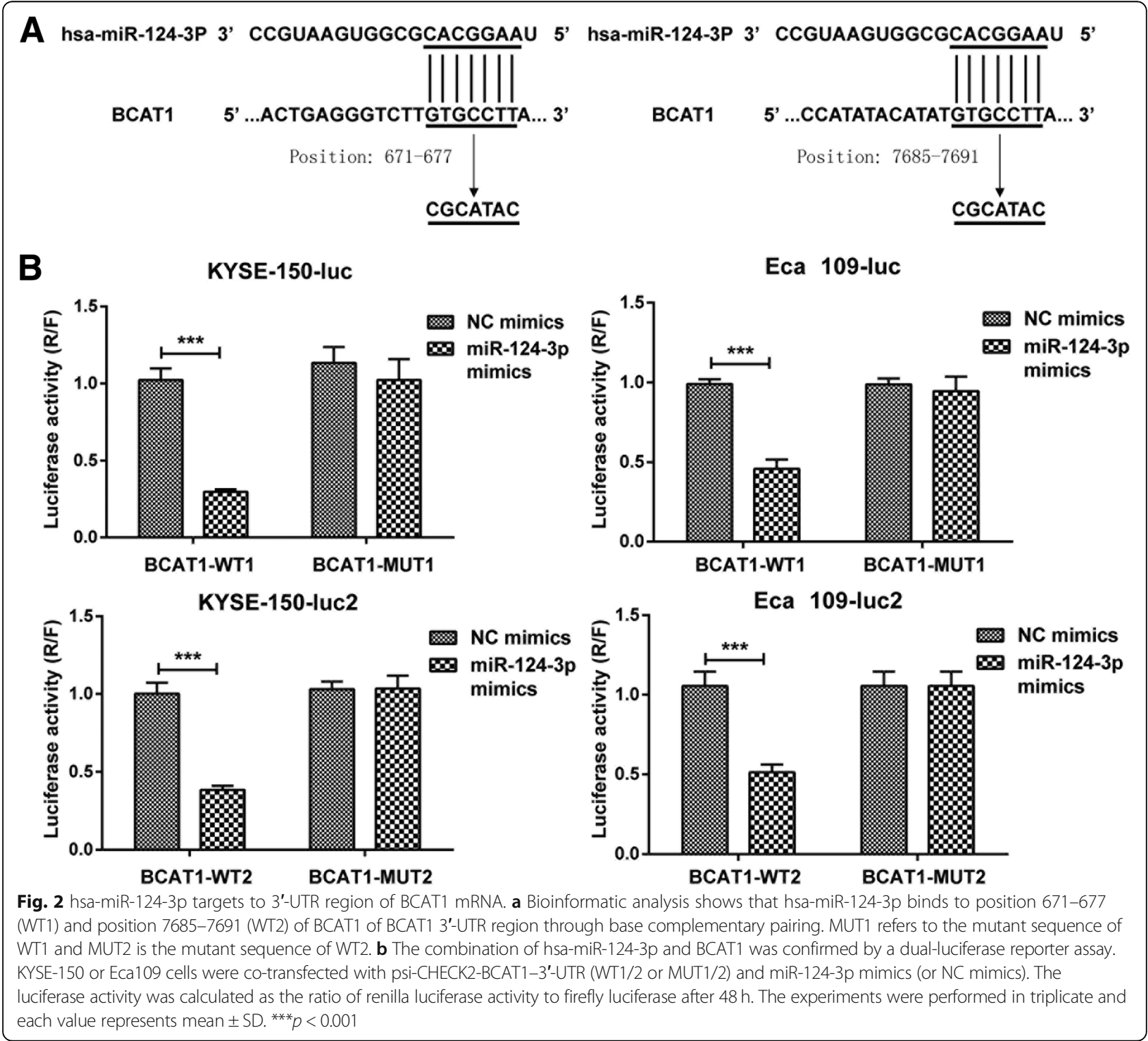


(Fig. 1b). Along the lines of reduced hsa-miR-124-3p mRNA expression, we also observed that the incidence of hsa-miR-124-3p hypermethylation in ESCC tissues was significantly higher than in normal tissues (Fig. 1c). Then, as shown in Fig. 1d, hypermethylation of hsamiR-124-3p was obvious in KYSE-150 and Eca109 cells, but not in normal HEEC cells. In addition, the clinical data indicated that low-level expression of hsa-miR-124$3 p$ was associated with tumor node metastasis (TNM) stage III-IV and poor differentiation grade (Fig. 1e and f)
- However, high expression of hsa-miR-124-3p was observed in the patients with TNM stage I-II and welldifferentiation grade. Therefore, there might be significant associations between hsa-miR-124-3p level and TNM stage, and differentiation grade.

\section{Hsa-miR-124-3p targets 3'UTR region of BCAT1 mRNA}

To determine the target gene of hsa-miR-124-3p, we used bioinformatics software of Miranda to predict its downstream target gene. The data showed that $5^{\prime}$-UTR

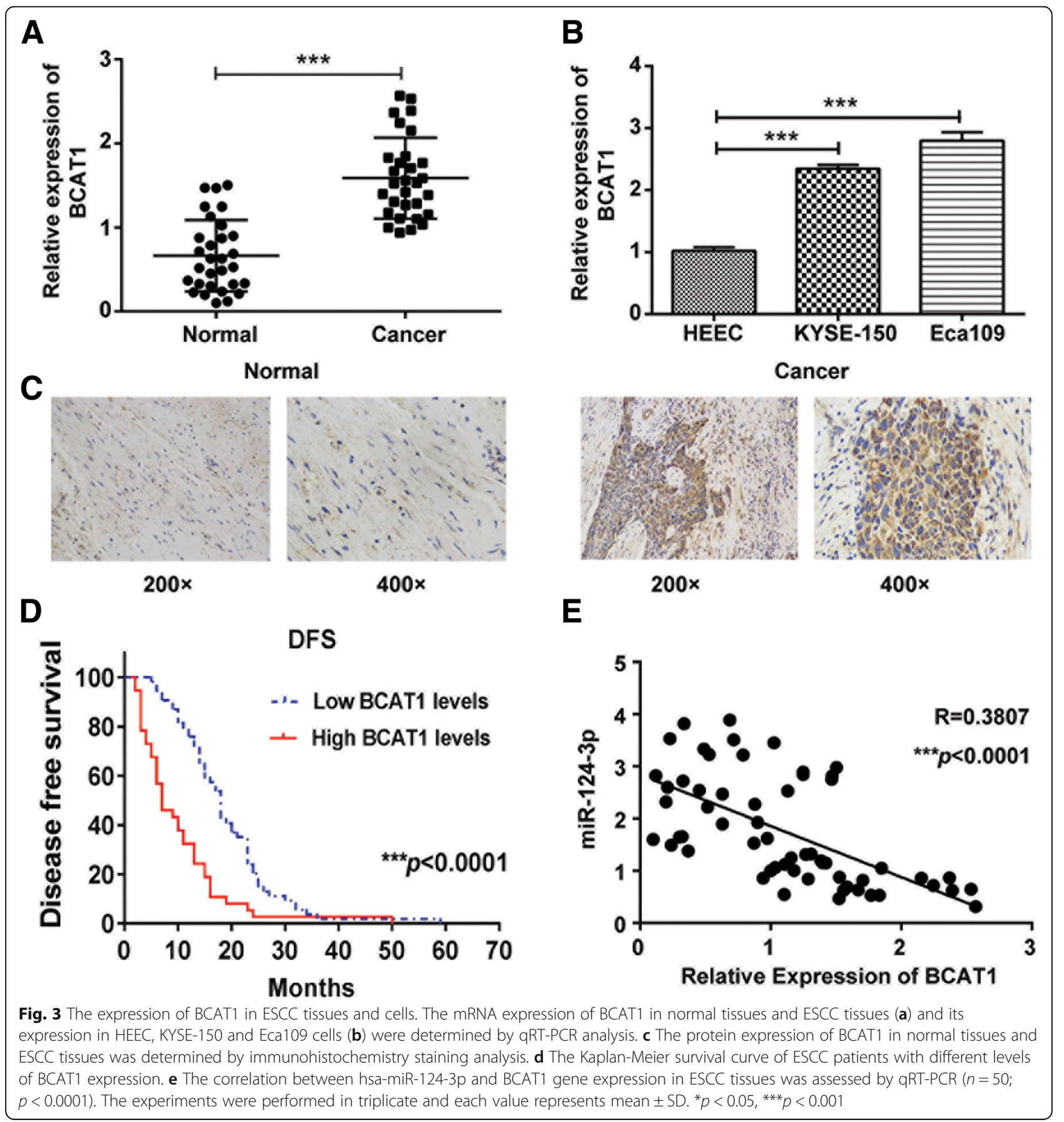


region of hsa-miR-124-3p could bind to 3'-UTR region of BCAT1 gene with two potential target sites of 671677 and 7685-7691 (Fig. 2a), which has been associated with cell proliferation, migration and invasion $[17,18]$. Subsequently, a dual-luciferase reporter assay was performed to confirm that BCAT1 mRNA is bona fide target of hsa-miR-124-3p. The data demonstrated that the relative luciferase activity of the BCAT1-WT1 3'UTR reporter was significantly inhibited in KYSE-150 and Eca109 cells with treatment of miR-124-3p mimics compared to the cells transfected with $\mathrm{NC}$ mimics. In contrast, the luciferase activity of BCAT1-MUT1 3'UTR reporter with the mutant binding site was unaffected by co-transfection of miR-124-3p mimics compared with NC mimics co-transfected. Similarly, the combination between BCAT1-WT2 3'UTR and hsa-miR-124-3p was also proved through dual-luciferase reporter assay (Fig. 2b).

BCAT1 is upregulated in ESCC tissues and cells and shows association with TNM stage, differentiation grade and survival

As BCAT1 was predicted to be the downstream target gene of hsa-miR-124-3p, we further studied the expression of BCAT1 in ESCC tissues and cells. As expected, the mRNA expression of BCAT1 was markedly increased in ESCC tissues compared with normal tissues (Fig. 3a). Meanwhile, its expression was also upregulated in KYSE-150 and Eca109 cells compared with HEEC cells (Fig. 3b). In agreement with the increased mRNA of BCAT1, BCAT1 protein expression was also significantly increased in ESCC tissues through the immunohistochemistry staining assay (Fig. 3c). Furthermore, the clinical data showed that BCAT1 protein expression level in ESCC was negatively associated with disease-free survival (Fig. 3d). In addition, the clinical data indicated that the expression of BCAT1 was significantly associated with tumor size, pathologic stage, $\mathrm{T}$ classification and differentiation grade of ESCC patients. However, there was no significant correlation between the expression level of BCAT1 and age, sex or N classification of ESCC patients (Table 1). Furthermore, the data demonstrated that miR-124-3p was of negative correlation with BCAT1 gene in ESCC tissues (Fig. 3e).

miR-124-3p mimics inhibits proliferation and migration of ESCC cells

To clarify miR-124-3p/BCAT1-mediated protection in ESCC, we first treated KYSE-150 or Eca109 cells with miR-124-3p mimics and NC mimics. As indicated in Fig. 4a, miR-124-3p mimics induced the mRNA expression of hsa-miR-124-3p and attenuated the mRNA expression of BCAT1 in KYSE-150 and Eca109 cells compared with NC mimics. At the same time, miR-124$3 p$ mimics also inhibited the protein expression of
Table 1 Clinicopathologic correlation of BCAT1 expression in ESCC cancer

\begin{tabular}{|c|c|c|c|}
\hline \multirow[t]{2}{*}{ Factors } & \multicolumn{3}{|c|}{ No. of patients (\%) } \\
\hline & $\begin{array}{l}\text { BCAT1 low } \\
\text { expression }\end{array}$ & $\begin{array}{l}\text { BCAT1 high } \\
\text { expression }\end{array}$ & $p$ \\
\hline$\overline{\text { Age }(y)}$ & & & 0.9626 \\
\hline$\geq 59$ & 28 & 19 & \\
\hline$<59$ & 26 & 18 & \\
\hline Sex & & & 0.2141 \\
\hline Male & 41 & 32 & \\
\hline Female & 13 & 5 & \\
\hline Tumor size (cm) & & & ${ }^{*} 0.0499$ \\
\hline$\geq 3$ & 30 & 28 & \\
\hline$<3$ & 24 & 9 & \\
\hline Pathologic stage (pTNM) & & & ${ }^{*} 0.0113$ \\
\hline । & 10 & 1 & \\
\hline$\|$ & 29 & 16 & \\
\hline III & 15 & 20 & \\
\hline T stage & & & ${ }^{*} 0.0233$ \\
\hline 1 & 9 & 1 & \\
\hline 2 & 12 & 6 & \\
\hline 3 & 31 & 28 & \\
\hline 4 & 2 & 2 & \\
\hline N stage & & & 0.1423 \\
\hline 0 & 37 & 19 & \\
\hline 1 & 14 & 12 & \\
\hline 2 & 3 & 6 & \\
\hline Differentiation grade & & & ${ }^{*} 0.0320$ \\
\hline Well & 9 & 3 & \\
\hline Moderate & 28 & 14 & \\
\hline Poor & 17 & 20 & \\
\hline
\end{tabular}

BCAT1 in KYSE-150 and Eca109 cells through western blotting analysis (Fig. 4b), which is in line with the result of immunofluorescence staining analysis (Fig. 4c). Next, we detected the effect of miR-124-3p mimics on proliferation and migration of ESCC cells. KYSE-150 and Eca109 cells treated with miR-124-3p mimics showed decreased cell viability compared to cells with $\mathrm{NC}$ mimics after $48 \mathrm{~h}$ and $72 \mathrm{~h}$ (Fig. 4d). Meanwhile, the treatment of miR-124$3 p$ mimics resulted in decreased colony formation in KYSE-150 and Eca109 cells (Fig. 4e). In addition, the cell migration of two ESCC cells indicated by transwell assay were significantly inhibited by miR-124-3p mimics transfection compared with $\mathrm{NC}$ mimics transfection (Fig. 4f). These results indicated that increased hsa-miR-124-3p might critically contribute to the inhibition of cell proliferation and migration in ESCC, which might be associated with the decreased expression of BCAT1. 


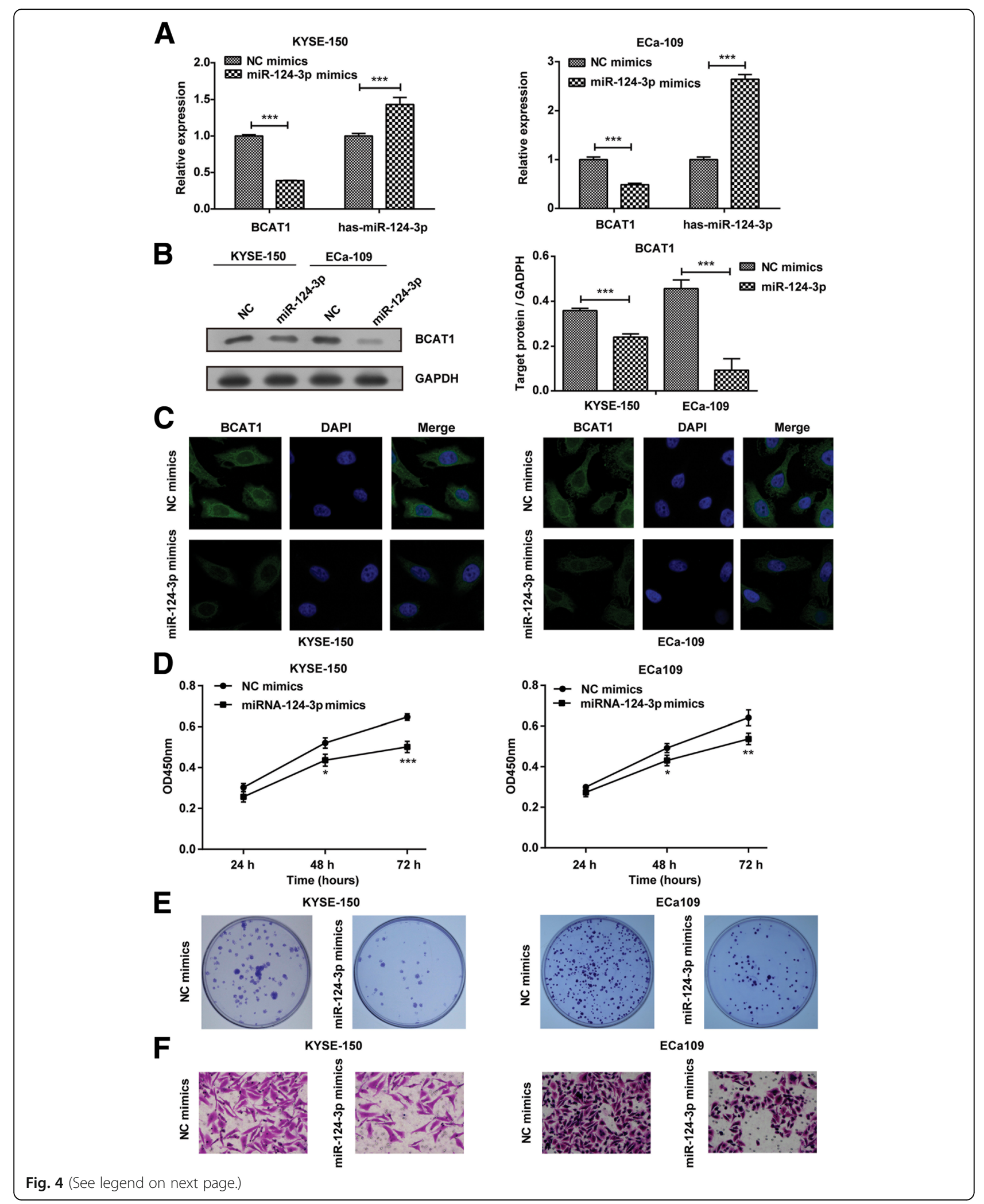


(See figure on previous page.)

Fig. 4 The effect of miR-124-3p mimics on cell proliferation and migration of ESCC cells. a The mRNA expression of BCAT1 and hsa-miR-124-3p in KYSE-150 and Eca109 cells transfected with miR-124-3p mimics or NC mimics were determined by qRT-PCR. b-c The protein expression of BCAT1 in KYSE-150 and Eca109 cells transfected with miR-124-3p mimics or NC mimics were detected by western blotting assay (b) and immunofluorescence staining assay (c). The target protein expression relative to GAPDH expression was displayed on the right of Fig. 4b. d-e The effect of miR-124-3p mimics on KYSE-150 and Eca109 cells proliferation was detected by CCK8 assay (d) and colony formation assay (e). f The effect of miR-124-3p mimics on KYSE-150 and Eca109 cells migration was detected by transwell assay. The experiments were performed in triplicate and each value represents mean \pm SD. ${ }^{*} P<0.05,{ }^{* *} P<0.01,{ }^{* * *} P<0.001$

Inhibition of proliferation and migration induced by hsamiR-124-3p was associated with the decreased BCAT1 expression

To determine whether hsa-miR-124-3p inhibition of cell proliferation and migration was associated with BCAT1 expression, we firstly explore the effect of BCAT1 on the proliferation and migration of ESCC cells. KYSE-150 and Eca109 cells were first transfected with BCAT1siRNA and NC siRNA. The results showed that compared to NC siRNA, BCAT1 siRNA treatment inhibited
mRNA expression of BCAT1 in two ESCC cells (Fig. 5a). Similar to the effect of miR-124-3p mimics transfection, knockdown of BCAT1 significantly inhibited cell viability (Fig. 5b), colony formation (Fig. 5c) and cell migration (Fig. 5d) in KYSE-150 and Eca109 cells. The result implies that BCAT1 is positively associated with proliferation and migration of ESCC cells.

Next, to confirm that hsa-miR-124-3p inhibition of cell proliferation and migration depends on BCAT1 expression. KYSE-150 or Eca109 cells were transfected with
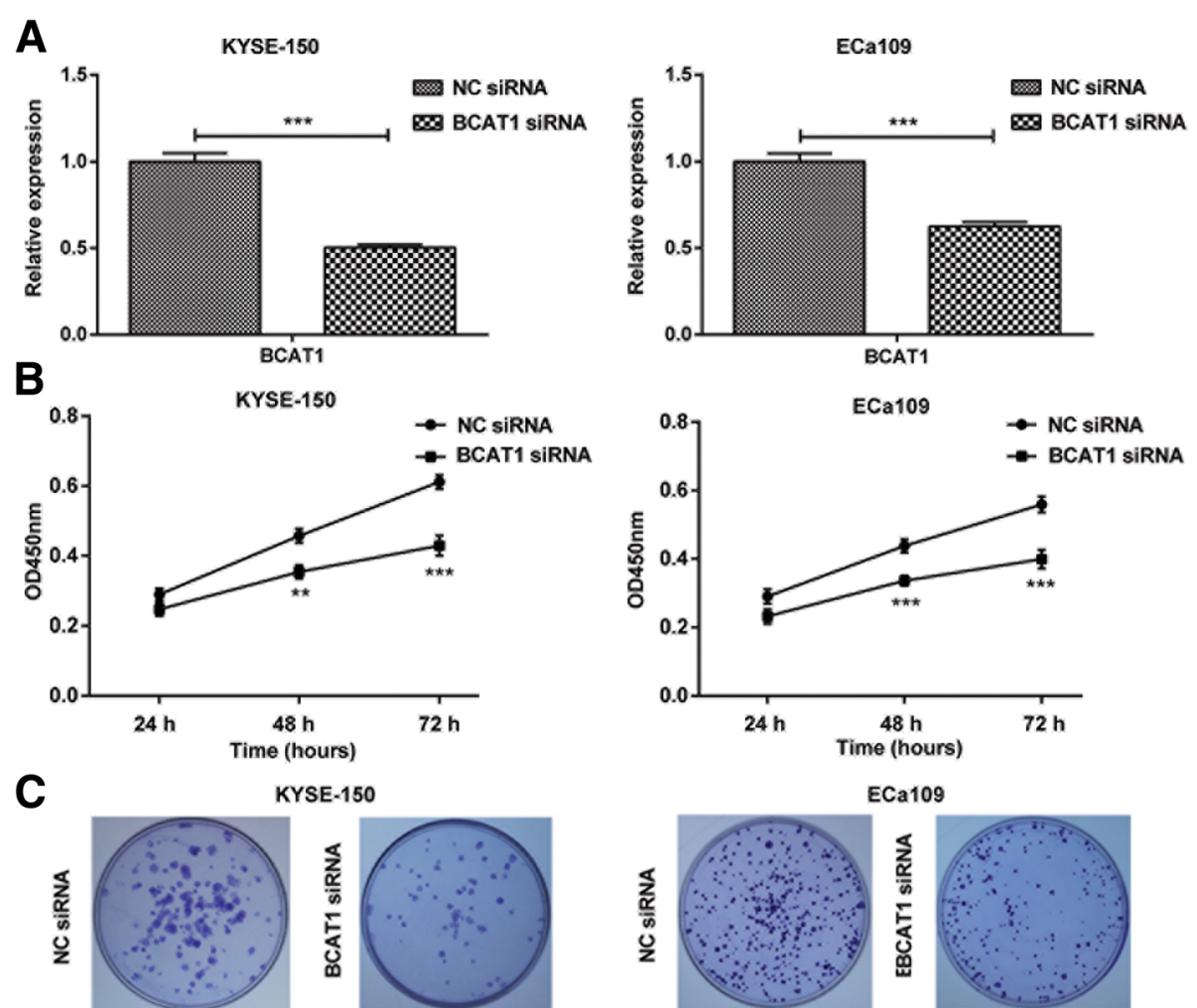

YSE-150

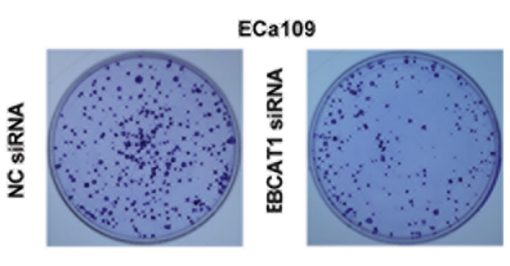

D
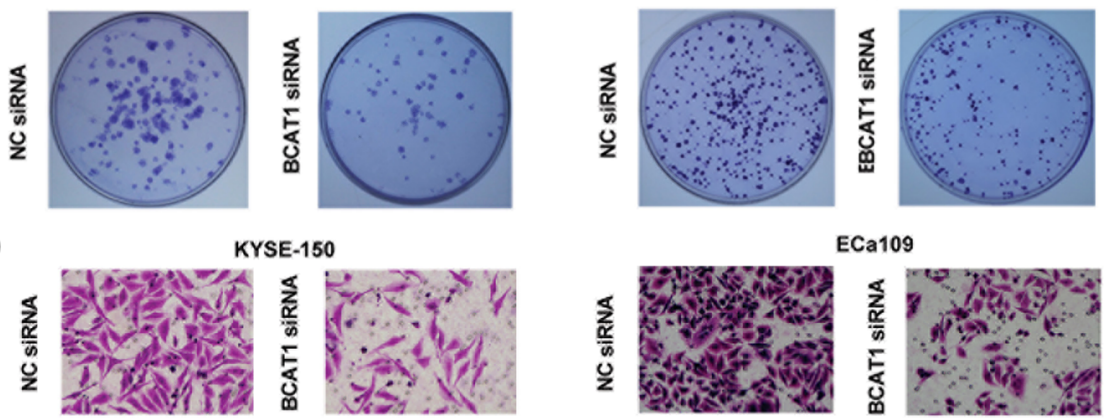

Fig. 5 The effect of BCAT1 siRNA on proliferation and migration of ESCC cells. a The mRNA expression of BCAT1 in KYSE-150 and Eca109 cells transfected with BCAT1 siRNA or NC siRNA were determined by qRT-PCR. $\mathbf{b}-\mathbf{c}$ The effect of BCAT1 siRNA on KYSE-150 and Eca109 cells proliferation was detected by CCK8 assay (b) and colony formation assay (c). $\mathbf{d}$ The effect of BCAT1 siRNA on KYSE-150 and Eca109 cells migration was detected by transwell assay. The experiments were performed in triplicate and each value represents mean \pm SD. ${ }^{*} P<0.05,{ }^{* *} P<0.01,{ }^{* * *} P<0.001$ 
OE-NC, OE-BACT1 or solvent control in the presence of hsa-miR-124-3p mimics. The results showed that BACT1 overexpression (OE-BACT1) enhanced migration (Fig. 6a) and proliferation (Fig. 6b-c), compared to the group OE-NC and solvent control. These finding suggests that hsa-miR-124-3p-medaited inhibition of proliferation and migration depends on the expression of BCAT1.

\section{DNMT1 regulates hsa-miR-124-3p / BCAT1 in ESCC cells}

As DNMT1 plays an important role in mediating the methylation of microRNAs in cancer cells [21, 22], we investigated whether it was involved in the regulation of hsa-miR-124-3p / BCAT1 in ESCC. Firstly, we found that DNMT1 mRNA expression was markedly increased in ESCC tissues (Fig. 7a) as well as two ESCC cell lines (KYSE-150 and Eca109 cells) (Fig. 7b). Next, as expected, the hsa-miR-124-3p was demethylated after treatment with $5 \mu \mathrm{M}$ 5-Azacitidine (5-Aza), the inhibitor of DNMT1, in KYSE-150 and Eca109 cells, which means DNMT1 contributes to the methylation of hsa-miR-1243p (Fig. 7c). Furthermore, 5-Aza treatment significantly promoted the mRNA expression of hsa-miR-124-3p and attenuated the mRNA expression of BCAT1 in KYSE150 and Eca109 cells (Fig. 7d). Meanwhile, it attenuated the protein expression of BCAT1 in these two ESCC cells as well (Fig. 7e).

In order to further confirm the regulatory role of DNMT1 to hsa-miR-124-3p / BCAT1 in ESCC cells, we treated KYSE-150 and Eca109 cells with DNMT1 siRNA. The data revealed that DNMT1 siRNA induced the demethylation of hsa-miR-124-3p and further promoted its mRNA expression in KYSE-150 and Eca109 cells (Fig. 8a and b). Accordingly, we found that the mRNA and protein expression of BCAT1 were both inhibited after treatment with DNMT1 siRNA compared with NC siRNA treatment (Fig. 8b-d). Collectively, these findings indicate that DNMT1 is essential for the methylation of hsa-miR-124-3p and subsequently induce the expression of BCAT1, which involves in the cell proliferation and migration of ESCC cells.

\section{Discussion}

MiR-124 has been shown to function as a tumor suppressor in esophageal cancer [12]. However, it is not clear concerning the mechanism by which miR-124 expression was downregulated in esophageal cancer and its subtype ESCC. In addition, there is still lack of direct experiment evidence suggesting that miR-124 as a tumor suppressor regulates the initiation and development of

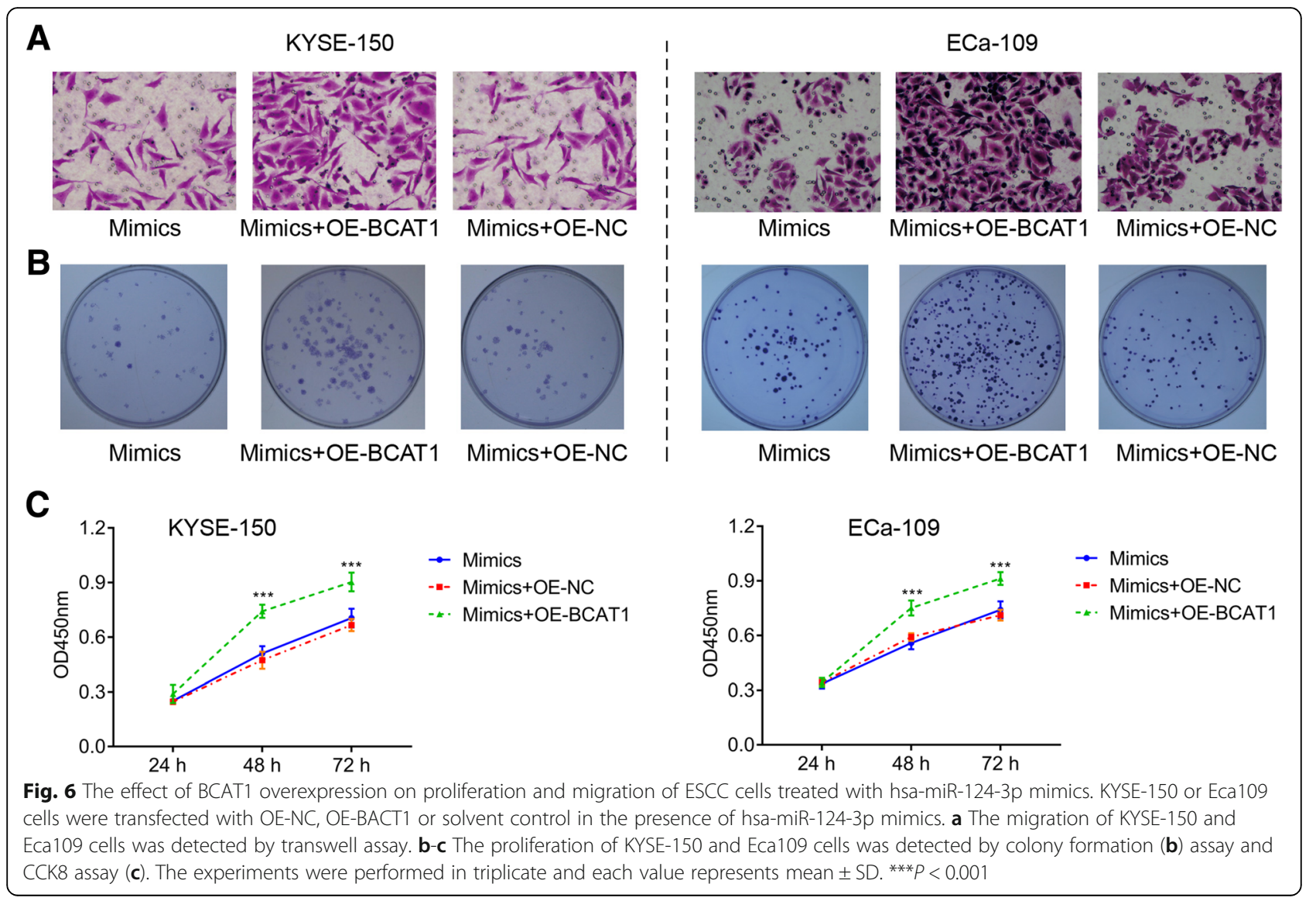



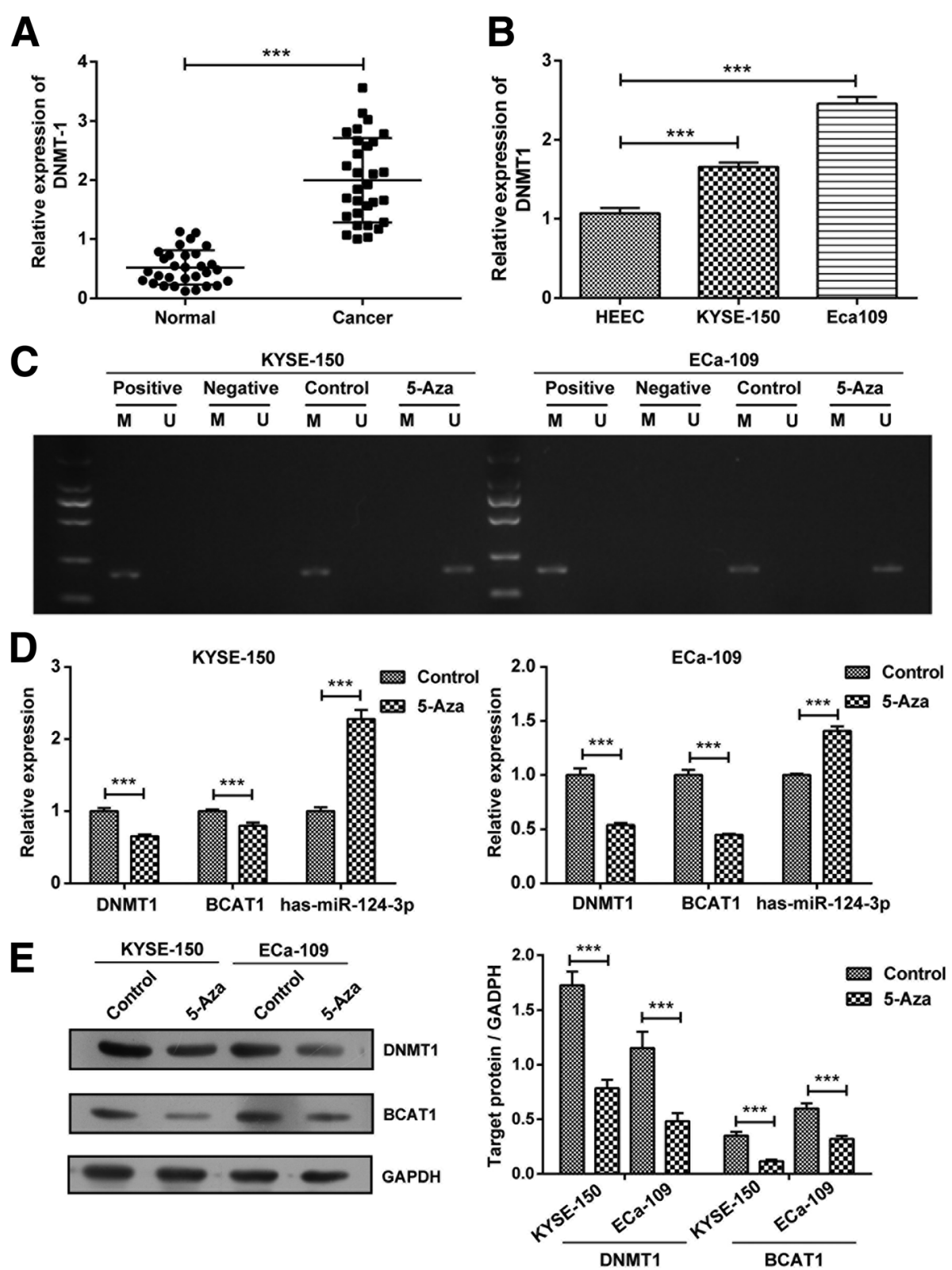

Fig. 7 The regulatory role of DNMT1 inhibitor on expression of hsa-miR-124-3p and BCAT1 in ESCC cells. $\mathbf{a}-\mathbf{b}$ The mRNA expression of DNMT1 in normal tissues and ESCC tissues (a) and its expression in HEEC, KYSE-150 and Eca109 cells (b) were determined by qRT-PCR analysis. c The methylation status of hsa-miR-124-3p in KYSE-150 and Eca109 cells treated with DNMT1 inhibitor 5 4M 5-Azacitidine (5-Aza) or its control (PBS), was detected by methylation specific PCR. $\mathbf{d}$ The mRNA expression of DNMT1, hsa-miR-124-3p and BCAT1 in KYSE-150 and Eca109 cells treated with 5-Aza or PBS were determined by qRT-PCR analysis. e The protein expression of DNMT1 and BCAT1 were detected by western blotting assay. The target protein expression relative to GAPDH expression was displayed on the right. The experiments were performed in triplicate and each value represents mean $\pm \mathrm{SD} .{ }^{* * *} P<0.001$

ESCC. We herein showed that significantly increased expression of hsa-miR-124-3p was observed in the paracancerous normal tissues of ESCC and the normal cell line HEEC compared to ESCC tissues and two ESCC cell lines. In addition, over-expression of hsa-miR-124$3 p$ is highly negatively correlated with proliferation and migration in several ESCC cells in the present study. These findings imply that decreased expression of hsa-
miR-124-3p might be highly correlated with initiation and progression of ESCC.

The first crucial insight gleaned from our present study is that although miR-124 has been reported to target several associated-cancer genes including RAC1, ROCK1 [23], STAT3, the androgen receptor [24], PIK3CA [25], EZH2 [26] and CBL [27], we showed a new target BCAT1 gene of hsa-miR-124-3p through bioinformatics prediction and 

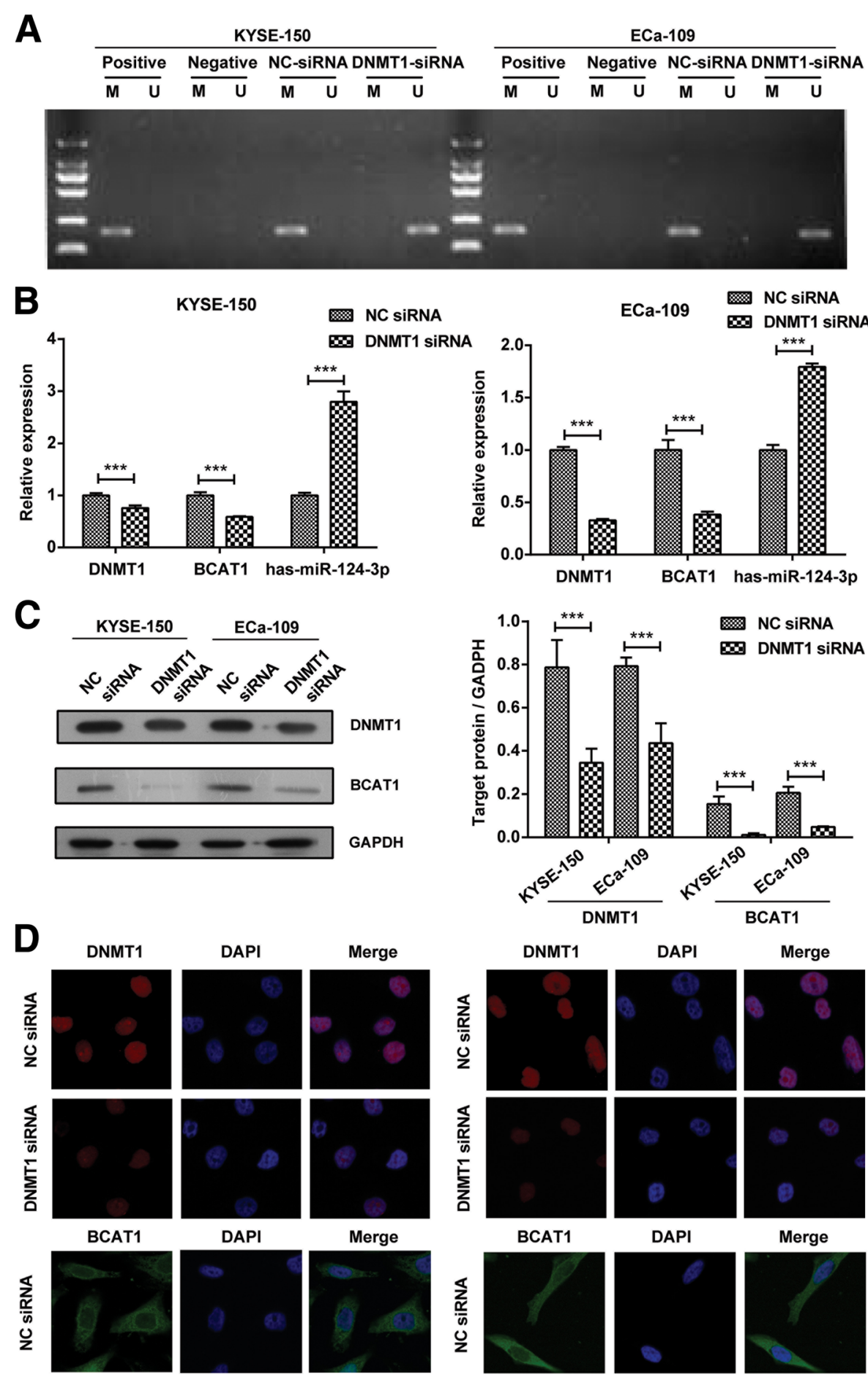

Merge

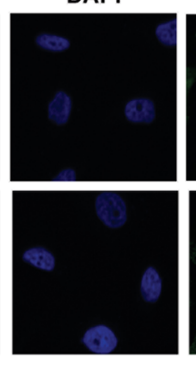

BCAT1

DAPI

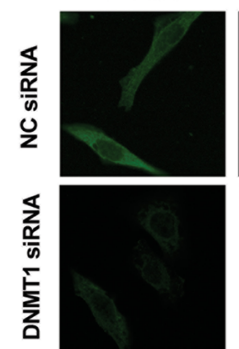

Merge

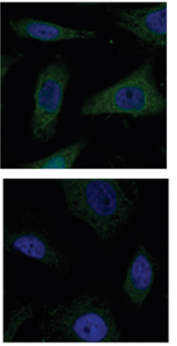

KYSE-150
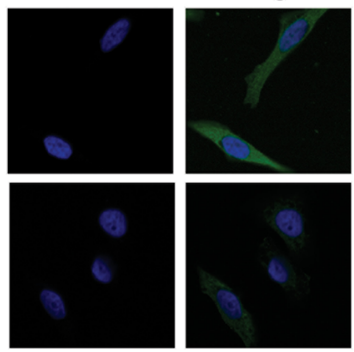

ECa-109

Fig. 8 (See legend on next page.) 
(See figure on previous page.)

Fig. 8 The regulatory role of DNMT1 siRNA on hsa-miR-124-3p / BCAT1 in ESCC cells. a The methylation status of hsa-miR-124-3p in KYSE-150 and Eca109 cells transfected with DNMT1 siRNA or NC siRNA was detected by methylation specific PCR. $\mathbf{b}$ The mRNA expression of DNMT1, hsa-miR-124-3p and BCAT1 in KYSE-150 and Eca109 cells transfected with DNMT1 siRNA or NC siRNA were determined by qRT-PCR analysis. c-d The protein expression of DNMT1 and BCAT1 were detected by western blotting assay (c) and immunofluorescence staining assay (d) respectively. The target protein expression relative to GAPDH expression was displayed on the right of Fig. 8c. The experiments were performed in triplicate and each value represents mean \pm SD. ${ }^{* * *} P<0.001$

dual-Luciferase reporter assay. The BCAT1 gene, known previously as ECA39, is an enzyme transforming $\alpha$-amino groups of branched chain amino acids (BCAAs) to aketoglutarates $(\mathrm{a}-\mathrm{KG})[15,16]$, yielding glutamate frequently required for the growth of malignant cells [28]. BCAT1 has been shown overexpression in some human malignancies, which is highly correlated with initiation and progression of malignant tumor [17, 18, 29]. However, to the best of our knowledge, there is no report showing association of BCAT1 overexpression with ESCC. We thus speculated that growth and migration inhibition in ESCC cells mediated by hsa-miR-124-3p was associated with downregulation of BCAT1 expression. Consistent with this, our results indicated that BCAT1 knockdown significantly inhibited cell proliferation and migration of ESCC cell lines KYSE-150 and Eca109.

Regulation of BCAT1 expression in different tumors involves in different mechanisms. The aberrant DNA methylation in BCAT1 promotor region was associated with in colorectal cancer, ovarian cancer and gliomas $[17,30]$. These findings suggest that epigenetic mechanisms could account for altered BCAT1 expression in different cancer types, including EOC. In the present study, however, we showed that BCAT1 expression was directly regulated by hsa-miR-124-3p since hsa-miR-124$3 p$ bound to 3 '-UTR region of BCAT1 gene, degrading BCAT1 mRNA. In fact, we also observed downregulation of BCAT1 expression in KYSE-150 and Eca109 cells treated with hsa-miR-124-3p mimics. It should be also noted that BCAT1 expression might be also regulated by DNA methylation in BCAT1 promotor region in KYSE150 and Eca109 cells although we did not provide the direct evidence. This is because expression of DNMT1, an enzyme that catalyzes the transfer of methyl groups to specific CpG structures in DNA, significantly increased in ESCC tissues and two ESCC cell lines.

Some miRNAs containing $\mathrm{CpG}$ islands are susceptible to methylation-associated silencing [31-33]. Methylationassociated silencing of tumor-suppressive miRNAs might play a crucial role in the tumorigenesis through activating oncogenic pathways. MiR-124, as a typical tumorsuppressive miRNA, has also been found epigenetically silenced in cholangiocarcinoma, cervical cancer and pancreatic cancer [34-36]. Similarly, a recent study showed that miR-124 gene were highly methylated in LNMpositive ESCC [10]. Those findings are in agreement with our results showing hypermethylation miR-124 gene in ESCC tissues and two ESCC cell lines. However, in the previous study it is unclear that hypermethylation in miR124 gene was linked to overexpression of DNMT in ESCC. In the present study, we provide the direct evidence suggesting that hypermethylation in miR-124 gene was strongly mediated by DNMT1 through DNMT1 knockdown and 5-AZ treatment. This finding is consistent with the previous study showing DNMT1-mediated downregulation of miR-124 expression in the intrahepatic cholangiocarcinoma [34]. Furthermore, our results demonstrated that DNMT1 knockdown or 5-AZ treatment significantly inhibited cell proliferation and migration of ESCC cell lines KYSE-150 and Eca109 through increasing hsa-miR-124-3p expression and inhibiting downstream BCAT1 expression.

\section{Conclusions}

In summary, our present work indicates that low hsamiR-124-3p levels mediated by DNMT1 promote ESCC cell proliferation and invasion by targeting BCAT1, suggesting that DNMT1/miR-124/ BCAT1 axis plays an important role in regulating development and progression of ESCC. These findings suggest that inhibitors against the activity of DNMT1 and/or BCAT1 might be a novel targeted therapeutic choice against ESCC.

\section{Abbreviations \\ 5'-Aza: 5'-Azacitidine; BCAAs: Branched chain amino acids; BCAT1: Branched chain amino acid transaminase 1; CCK-8: Cell Counting Kit-8; DAPI: 4,6- \\ diamino-2-phenyl indole; DNMTs: DNA methyltransferases; ESCC: Esophageal squamous cell carcinoma; FITC: Fluoresceine isothiocyanate; \\ GAPDH: Glyceraldehyde-3-phosphate dehydrogenase; HOXB2: Homeobox protein Hox-B2; MiRNAs: microRNAs; MSP: Methylation Specific PCR; NC: Negative control; NEFL: Neurofilament light polypeptide; OBSL1: Obscurin-like 1; SLC15A3: Solute carrier family 15 member 3; TNM: Tumor Lymph Node Metastasis; UTR: Untranslated Region}

\section{Acknowledgements}

Not applicable.

\section{Authors' contributions}

$B Z, X Z, J L Z, Y Y L, H H L$ and YFF designed and performed the experiments. BZ, ZWW, HSZ, MYF, DWZ and YYL analysed and interpreted the data. BZ, HHL, YYF and $Y Y L$ wrote the paper. All authors have read and approved the manuscript.

\section{Funding}

Not applicable.

\section{Availability of data and materials}

The data used and analyzed during this study are available from the corresponding author on request. 


\section{Ethics approval and consent to participate}

The study was obtained the informed consent from all the participating patients and the approval from the Ethics Committee of the First Affiliated Hospital, Sun Yat-sen University. The ethics approval for cells is not needed in this study.

\section{Consent for publication}

Not applicable.

\section{Competing interests}

The authors declare that they have no competing interests.

\section{Author details}

'Department of Thoracic Surgery, the First Affiliated Hospital, Sun Yat-sen University, Guangzhou, China. ${ }^{2}$ Department of Burns, the First Affiliated Hospital, Sun Yat-sen University, Guangzhou, China. ${ }^{3}$ Department of Gastrointestinal Surgery, the First Affiliated Hospital, Sun Yat-sen University, Guangzhou, China. ${ }^{4}$ Surgical and anesthesia center, the First Affiliated Hospital, Sun Yat-sen University, Guangzhou, China. ${ }^{5}$ State Key Laboratory of Oncology in South China, Collaborative Innovation Center for Cancer Medicine, Sun Yat-sen University Cancer Center, Guangzhou, China. ${ }^{6}$ Department of Pathology, Sun Yat-sen University Cancer Center, Guangzhou, China. ${ }^{7}$ Guangzhou, China.

\section{Received: 19 February 2019 Accepted: 10 June 2019}

\section{Published online: 21 June 2019}

\section{References}

1. Rustgi AK, El-Serag HB. Esophageal carcinoma. N Engl J Med. 2014;371(26): 2499-509.

2. Stewart B, Wild CP: World cancer report 2014. Health 2017.

3. Pennathur A, Gibson MK, Jobe BA, Luketich JD. Oesophageal carcinoma. Lancet. 2013;381(9864):400-12.

4. Kelly TK, De Carvalho DD, Jones PA. Epigenetic modifications as therapeutic targets. Nat Biotechnol. 2010;28(10):1069.

5. Portela A, Esteller M. Epigenetic modifications and human disease. Nat Biotechnol. 2010;28(10):1057.

6. Feinberg AP, Koldobskiy MA, Göndör A. Epigenetic modulators, modifiers and mediators in cancer aetiology and progression. Nat Rev Genet. 2016; 17(5):284.

7. Schübeler D. Function and information content of DNA methylation. Nature. 2015;517(7534):321.

8. Jemal A, Bray F, Center MM, Ferlay J, Ward E, Forman D. Global cancer statistics. CA Cancer J Clin. 2011;61(2):69-90.

9. Jones PA, Baylin SB. The epigenomics of cancer. Cell. 2007;128(4):683-92.

10. Nagata H, Kozaki K-I, Muramatsu T, Hiramoto H, Tanimoto K, Fujiwara N, Imoto S, Ichikawa D, Otsuji E, Miyano S. Genome-wide screening of DNA methylation associated with lymph node metastasis in esophageal squamous cell carcinoma. Oncotarget. 2017:8(23):37740.

11. Di Leva G, Garofalo M, Croce CM. MicroRNAs in cancer. Ann Rev Pathol. 2014;9:287-314.

12. Cheng Y, Li Y, Nian Y, Liu D, Dai F, Zhang J. STAT3 is involved in miR-124mediated suppressive effects on esophageal cancer cells. BMC Cancer. 2015; 15(1):306.

13. Zhang J, Huang $X$, Xiao J, Yang $Y$, Zhou $Y$, Wang $X$, Liu Q, Yang J, Wang $M$, Qiu L. Pri-miR-124 rs531564 and pri-miR-34b/c rs4938723 polymorphisms are associated with decreased risk of esophageal squamous cell carcinoma in Chinese populations. PLoS One. 2014:9(6):e100055.

14. Lewis BP, Burge CB, Bartel DP. Conserved seed pairing, often flanked by adenosines, indicates that thousands of human genes are microRNA targets. Cell. 2005;120(1):15-20.

15. ICHIHARA A, KOYAMA E. Transaminase of branched chain amino acids. J Biochem. 1966;59(2):160-9.

16. Taylor RT, Jenkins WT. Leucine aminotransferase II. Purification and characterization. J Biol Chem. 1966;241(19):4396-405.

17. Tönjes M, Barbus S, Park YJ, Wang W, Schlotter M, Lindroth AM, Pleier SV, Bai AH, Karra D, Piro RM. BCAT1 promotes cell proliferation through amino acid catabolism in gliomas carrying wild-type IDH1. Nat Med. 2013;19(7):901.

18. Zhou W, Feng X, Ren C, Jiang X, Liu W, Huang W, Liu Z, Li Z, Zeng L, Wang L. Over-expression of BCAT1, a c-Myc target gene, induces cell proliferation, migration and invasion in nasopharyngeal carcinoma. Mol Cancer. 2013; 12(1):53.

19. Wang Z-Q, Faddaoui A, Bachvarova M, Plante M, Gregoire J, Renaud M-C, Sebastianelli A, Guillemette C, Gobeil S, Macdonald E. BCAT1 expression associates with ovarian cancer progression: possible implications in altered disease metabolism. Oncotarget. 2015;6(31):31522.

20. Xu M, Liu Q, Jia Y, Tu K, Yao Y, Liu Q, Guo C. BCAT1 promotes tumor cell migration and invasion in hepatocellular carcinoma. Oncol Lett. 2016;12(4): 2648-56.

21. Zhou D, Wan Y, Xie D, Wang Y, Wei J, Yan Q, Lu P, Mo L, Xie J, Yang S. DNMT1 mediates chemosensitivity by reducing methylation of miRNA-20a promoter in glioma cells. Exp Mol Med. 2015;47(9):e182.

22. Ning X, Shi Z, Liu X, Zhang A, Han L, Jiang K, Kang C, Zhang Q. DNMT1 and EZH2 mediated methylation silences the microRNA-200b/a/429 gene and promotes tumor progression. Cancer Lett. 2015;359(2):198-205.

23. Hu C-B, Li Q-L, Hu J-F, Zhang Q, Xie J-P, Deng L. miR-124 inhibits growth and invasion of gastric cancer by targeting ROCK1. Asian Pac J Cancer Prev. 2014;15(16):6543-6.

24. Shi X-B, Xue L, Ma A-H, Tepper CG, Gandour-Edwards R, Kung H-J, deVere White RW. Tumor suppressive miR-124 targets androgen receptor and inhibits proliferation of prostate cancer cells. Oncogene. 2013;32(35):4130.

25. Lang Q, Ling C. MiR-124 suppresses cell proliferation in hepatocellular carcinoma by targeting PIK3CA. Biochem Biophys Res Commun. 2012 426(2):247-52.

26. Zheng F, Liao Y-J, Cai M-Y, Liu Y-H, Liu T-H, Chen S-P, Bian X-W, Guan X-Y, Lin MC, Zeng $Y$-X. The putative tumour suppressor microRNA-124 modulates hepatocellular carcinoma cell aggressiveness by repressing ROCK2 and EZH2. Gut. 2012;61(2):278-89.

27. Xia J, Wu Z, Yu C, He W, Zheng H, He Y, Jian W, Chen L, Zhang L, Li W. miR124 inhibits cell proliferation in gastric cancer through down-regulation of SPHK1. J Pathol. 2012;227(4):470-80.

28. Eagle H. Nutrition needs of mammalian cells in tissue culture. Science. 1955; 122(3168):501-4.

29. Zhang EY, Cristofanilli M, Robertson F, Reuben JM, Mu Z, Beavis RC, Im H, Snyder M, Hofree M, Ideker T. Genome wide proteomics of ERBB2 and EGFR and other oncogenic pathways in inflammatory breast cancer. J Proteome Res. 2013;12(6):2805-17.

30. Mitchell SM, Ross JP, Drew HR, Ho T, Brown GS, Saunders NF, Duesing KR, Buckley MJ, Dunne R, Beetson I. A panel of genes methylated with high frequency in colorectal cancer. BMC Cancer. 2014;14(1):54.

31. Chuang JC, Jones PA. Epigenetics and microRNAs. Pediatr Res. 2007;61(5 Part 2):24R.

32. Saito $Y$, Jones PM. Epigenetic activation of tumor suppressor microRNAs in human cancer cells. Cell Cycle. 2006;5(19):2220-2.

33. Murakami Y, Yasuda T, Saigo K, Urashima T, Toyoda H, Okanoue T, Shimotohno K. Comprehensive analysis of microRNA expression patterns in hepatocellular carcinoma and non-tumorous tissues. Oncogene. 2006;25(17):2537.

34. Zeng B, Li Z, Chen R, Guo N, Zhou J, Zhou Q, Lin Q, Cheng D, Liao Q, Zheng $L$. Epigenetic regulation of miR-124 by hepatitis $C$ virus core protein promotes migration and invasion of intrahepatic cholangiocarcinoma cells by targeting SMYD3. FEBS Lett. 2012;586(19):3271-8.

35. Wilting SM, van Boerdonk RA, Henken FE, Meijer CJ, Diosdado B, Meijer GA, le Sage C, Agami R, Snijders PJ, Steenbergen RD. Methylation-mediated silencing and tumour suppressive function of hsa-miR-124 in cervical cancer. Mol Cancer. 2010:9(1):167.

36. Wang P, Chen L, Zhang J, Chen H, Fan J, Wang K, Luo J, Chen Z, Meng Z, Liu L. Methylation-mediated silencing of the miR-124 genes facilitates pancreatic cancer progression and metastasis by targeting Rac1. Oncogene. 2014;33(4):514.

\section{Publisher's Note}

Springer Nature remains neutral with regard to jurisdictional claims in published maps and institutional affiliations. 